\title{
Effects of social support during parturition on maternal and infant morbidity
}

\author{
MARSHALL H KLAUS, JOHN H KENNELL, STEVEN S ROBERTSON, ROBERTO SOSA
}

\begin{abstract}
Because continuous social support during labour is a component of care in many societies but inconsistent in our own, the clinical effect of support during labour on maternal and neonatal morbidity were studied. Social support was provided by female companions. Four hundred and sixty five healthy primigravidous women were enrolled using a randomised design. Compared with 249 women undergoing labour alone 168 women who had supportive female companions throughout labour had significantly fewer perinatal complications $(\mathbf{p}<\mathbf{0 . 0 0 1})$, including caesarean sections $(7 \% v 17 \%, p<0.01)$ and oxytocin augmentation $(2 \% v 13 \%, p<0.001)$, and fewer infants admitted to neonatal intensive care $(\mathbf{p}<0 \cdot 10)$. Of the women who had an uncomplicated labour and delivery requiring no interventions, those with a companion had a significantly shorter duration of labour $(7 \cdot 7$ hours $v 15.5$ hours, $\mathrm{p}<0.001$ ).
\end{abstract}

This study suggests that constant human support may be of great benefit to women during labour.

\section{Introduction}

Developments in medical care during the past 75 years have altered childbirth remarkably, drastically changing routines and customs that had evolved over centuries. The place of birth has shifted from the home to the hospital, and many practices have altered, including birth position, obstetric medication, fetal monitoring, and companionship during labour. ${ }^{1}$ As a result, many mothers in hospitals in the West spend varying periods of time during labour alone. We

Department of Pediatrics and Human Development, B240 Life Sciences Building, Michigan State University, East Lansing, MI 48824, USA MARSHALL H KLAUS, MD, professor

Department of Pediatrics, Case Western Reserve School of Medicine, Cleveland, Ohio 44106, USA

JOHN H KENNELL, MD, professor

STEVEN S ROBERTSON, PHD, assistant professor

All Children's Hospital, St Petersburg, FL 33701

ROBERTO SOSA, MD, assistant professor

Correspondence and requests for reprints to: Dr Klaus. report the results of a randomised, controlled study of the effect of a supportive companion staying with women throughout labour.

\section{Patients and methods}

At the Social Security Hospital in Guatemala we enrolled 465 full term healthy primigravidous women in early labour who had a cervical dilatation of $3 \mathrm{~cm}$ or less and were without medical problems. All women were initially admitted to a large labour room. After agreeing to participate in the study each woman was randomly assigned to either the control group $(n=279)$ or the experimental group $(n=186)$, according to the contents of a sealed opaque envelope. Each envelope was numbered sequentially to prevent improper assignment. Because of the increased number of perinatal problems in a similar control group during an earlier pilot study ${ }^{2}$ the pool of envelopes contained more assignments to the control group to ensure similar sized groups of patients with uncomplicated labours and delivery for follow up.

The women remained in the large labour ward until their cervical dilatation was 3 to $4 \mathrm{~cm}$; they were then transferred to labour rooms adjoining the delivery unit. The control group followed the usual hospital routines and, because the unit has $50-60$ deliveries/ 24 hours, did not receive any consistent support. The women in the experimental group received constant support and companionship from one of three lay Guatemalan women with no obstetric training. (We called these women "doulas" after a Greek word meaning "woman's servant"; the term has been used previously to describe a woman assisting the mother at home after birth. ${ }^{3}$ ) Social support was given from admission to delivery in addition to the routine care. It was both emotional and physical, and included rubbing the patient's back, holding her hands, and providing explanation and encouragement. The patient was told that she would never be left alone. Obstetric care for both groups was determined by the course of individual patients. Clinical decisions on this busy service were made by doctors who to our knowledge were unaware of the study and previous work by our research group.

We recorded the duration of labour, the use of oxytocin or forceps, and any evidence of fetal distress during labour or delivery that necessitated a caesarean section. We also noted if the infant was asphyxiated (that is, had an Apgar score below eight at one and five minutes), was meconium stained, or showed evidence of illness such as respiratory distress. Mother-infant pairs were excluded when the mother developed a complication during labour, delivery, or post partum that required special care-for instance, afibrinogenaemia, retention of the placenta (five experimental and five control)-if the baby's weight was below 5.5 pounds (two experimental and eight control) or above 8 pounds ( 11 experimental and 15 control), or if the baby had a pre-existing problem unrelated to labour or delivery-twins (one control) and congenital malformation (one control). This resulted in final sample sizes of 249 in the control and 168 in the experimental group. 


\section{Results}

Fewer mothers in the experimental group (27\%) than in the control group $(59 \%)$ developed problems during labour $\left(\chi^{2}(1)=40 \cdot 7, p<0.001\right)$. Considering only the first problem occurring in labour or delivery (table I) the prevalence of a caesarean section was lower in the experimental group $(7 \%)$ than in the control group $(17 \%)\left(\chi^{2}(1)=9.3, p<0.01\right)$. The use of oxytocin to augment labour was also less common in the experimental group $(2 \% v 13 \%$, $\left.\chi^{2}(1)=13.4, p<0.001\right)$. When all cases were counted-for example, caesarean section might have been performed after another problem was identified-the prevalence of these two interventions was still greater in the control group than in the experimental group (caesarean sections $7 \% v 19 \%$; oxytocin $2 \% v 15 \%$ ).

TABLE I-No (\%) of patients who experienced perinatal problems during labour and delivery

\begin{tabular}{lccc}
\hline \multicolumn{1}{c}{ Problems } & $\begin{array}{c}\text { No support } \\
(\mathrm{n}=249)\end{array}$ & $\begin{array}{c}\text { Support } \\
(\mathrm{n}=168)\end{array}$ & Significance \\
\hline Caesarean section & $43(17)$ & $11(7)$ & $\mathrm{p}<0.01$ \\
Meconium staining & $44(18)$ & $21(13)$ & \\
Asphyxia & $8(3)$ & $4(2)$ & \\
Oxytocin & $33(13)$ & $4(2)$ & $\mathrm{p}<0.001$ \\
Analgesia & $10(4)$ & $2(1)$ & \\
Forceps & $7(3)$ & $2(1)$ & \\
Other & $2(1)$ & $1(1)$ & \\
\hline Total & $147(59)$ & $45(27)$ & $\mathrm{p}<0.001$ \\
\hline No problems & $102(41)$ & $123(73)$ & \\
\hline
\end{tabular}

Log linear analysis of a four way classification of mothers (table II) based on marital state (single or living together), cervical dilatation $(1,2$, or $3 \mathrm{~cm}$ ) on admission, support (present or absent), and perinatal problems (present or absent) was used to assess the effect of companionship after taking into account background variables. ${ }^{4}$ A stepwise procedure was used, with problems treated as the dependent variable. Marital state and cervical dilatation were entered first and constituted a significant improvement $\left(\chi^{2}\right.$ (3) $=14.8, p<0.01$ ) over the base model (in which the prevalence of perinatal problems was considered to be independent of all other variables). The support variable was entered next, and its inclusion constituted a significant improvement $\left(\chi^{2}(1)=143.6, p<0.001\right)$ over the model that included only marital state and dilatation. A small but significant further improvement $\left(\chi^{2}\right.$ $(1)=5.5, p<0.05)$ was obtained by including the interaction of marital state and the treatment variable, suggesting that the effect of support might depend on marital state. The effect of a companion was greater on women living alone.

For the 225 women with an uncomplicated labour and delivery requiring no interventions there were differences between the two groups in the duration of labour (table III). Women with support had a mean (SD) labour of $7 \cdot 7(3.5)$ hours, whereas the women without support had a labour of $15 \cdot 5$ $(7 \cdot 0)$ hours, $(t\{223\}=-10.58, p<0.001)$. The women who had doulas were also slightly older $(20.3(2.6)$ years $v 19.5(2.5)$ years, $t(223)=2.32$, $\mathrm{p}<0.05)$ and more dilated on admission $(1.9(0.8) \mathrm{cm} \mathrm{v} 1.5(0.7) \mathrm{cm}, t$ $(223)=4.47, p<0.001)$. About half of the women in each group were single ( $54 \%$ in the group with doulas, $51 \%$ in the control group).

TABLE II-Classification of women based on marital state, cervical dilatation on admission, support, and perinatal problems

\begin{tabular}{|c|c|c|c|c|}
\hline \multirow{3}{*}{$\begin{array}{l}\text { Cervical } \\
\text { Dilatation } \\
(\mathrm{cm})\end{array}$} & \multicolumn{2}{|c|}{ No support } & \multicolumn{2}{|c|}{ Support } \\
\hline & \multicolumn{2}{|c|}{ Problems } & \multicolumn{2}{|c|}{ Problems } \\
\hline & 0 & $\geqslant 1$ & 0 & $\geqslant 1$ \\
\hline & \multicolumn{4}{|c|}{ Living together } \\
\hline 1 & 27 & 38 & 28 & 5 \\
\hline 2 & 8 & 18 & 28 & 5 \\
\hline 3 & 4 & 6 & 15 & 1 \\
\hline \multirow[t]{2}{*}{ Total } & 39 & 62 & 71 & 11 \\
\hline & \multicolumn{4}{|c|}{ Single } \\
\hline 1 & 20 & 65 & 27 & 3 \\
\hline 2 & 12 & 34 & 27 & 2 \\
\hline 3 & 3 & 14 & 26 & 1 \\
\hline Total & 35 & 113 & 80 & 6 \\
\hline
\end{tabular}

TABLE III-Duration of labour in women with uncomplicated labour and delivery requiring no intervention

\begin{tabular}{|c|c|c|c|c|}
\hline \multirow[b]{2}{*}{$\begin{array}{c}\text { Cervical } \\
\text { dilatation } \\
(\mathrm{cm})\end{array}$} & \multicolumn{2}{|c|}{ No support } & \multicolumn{2}{|c|}{ Support } \\
\hline & $\begin{array}{l}\text { Number of } \\
\text { patients }\end{array}$ & $\begin{array}{c}\text { Mean (SD) } \\
\text { duration of } \\
\text { labour } \\
\text { (hours) }\end{array}$ & $\begin{array}{l}\text { Number of } \\
\text { patients }\end{array}$ & $\begin{array}{c}\text { Mean (SD) } \\
\text { duration of } \\
\text { labour } \\
\text { (hours) }\end{array}$ \\
\hline & \multicolumn{4}{|c|}{ Living together } \\
\hline 1 & 34 & $16 \cdot 7(8 \cdot 1)$ & 21 & $9 \cdot 1(2 \cdot 9)$ \\
\hline 2 & 12 & $14 \cdot 2(7 \cdot 3)$ & 23 & $6.9(3.6)$ \\
\hline 3 & 4 & $16.8(7 \cdot 6)$ & 12 & $6.8(2.9)$ \\
\hline & \multicolumn{4}{|c|}{ Single } \\
\hline 1 & 29 & $16 \cdot 2(6 \cdot 0)$ & 21 & $9 \cdot 6(4 \cdot 5)$ \\
\hline 2 & 16 & $13.9(6.0)$ & 24 & $7 \cdot 5(3 \cdot 3)$ \\
\hline 3 & 7 & $9 \cdot 6(3 \cdot 2)$ & 22 & $6 \cdot 2(2 \cdot 6)$ \\
\hline
\end{tabular}

Stepwise regression analysis (table IV), in which the background variables (maternal age and marital state) and cervical dilatation on admission were entered first, confirmed the effect of the social support. For the women whose labour and delivery were without complications or medical interventions $12 \%$ of the variance in the duration of labour could be attributed to the background variables and initial dilatation while social support accounted for an additional $25 \%$. Similar differences in the duration of labour were obtained for the $\mathbf{9 2}$ women with problems, excluding those with interventions that directly influenced its duration-for example, caesarean section, oxytocin, and use of forceps.

The health of the two groups of infants at birth also differed. More infants of mothers in the control group were transferred to a neonatal intensive care unit than infants of mothers with social support $\left(7 \% v 2 \%, \chi^{2}=3 \cdot 3, p=0 \cdot 07\right)$. These results should be interpreted with caution because of the small sample size and the lack of other facilities for closely observing transitional problems of the neonate: all infants with any type of problem were sent to the neonatal intensive care unit. Reasons for transfer included respiratory problems (nine infants) problems associated with meconium in the amniotic fluid (eight), asphyxia (two), hypoglycaemia (one), and jaundice shortly after birth (one).

TABLE IV-Stepwise regression analysis of duration of labour in women with uncomplicated labour and delivery requiring no intervention

\begin{tabular}{ccccc}
\hline & Variable & \multicolumn{3}{c}{ Cumulative } \\
\cline { 3 - 5 } Step & added & \multicolumn{1}{c}{$\mathbf{r}^{\star}$} & $\mathbf{R}^{2}$ & $\Delta \mathbf{R}^{2}$ \\
\hline 1 & Maternal age & 0.007 & 0.000 & 0.000 \\
2 & Marital state & -0.071 & 0.005 & 0.005 \\
3 & Dilatation & -0.357 & 0.128 & $0.123 \dagger$ \\
4 & Social support & -0.578 & 0.383 & $0.254 \dagger$ \\
\hline
\end{tabular}

$\star$ Zero order correlation between each variable and duration of labour. $t p<0.001$.

\section{Discussion}

Our results show the benefits associated with the introduction of support during labour in a population of poor women who routinely undergo labour alone in a crowded ward. This study replicated and substantially extended the results of our previous study of 133 women in this same population, in which continuous social support was found unexpectedly to reduce the duration of labour from $19 \cdot 3$ to 8.7 hours and to decrease the prevalence of overall perinatal complications from $76 \%$ to $37 \% .^{2}$

Continuous social support by women has been a birth practice in most cultures but has not been routinely provided in the West. In 127 of 128 societies from which data are available a woman is present throughout labour with the mother to be. ${ }^{5}$ Studies of support during Lamaze childbirth can be criticised because of unsatisfactory selection of a control population. There are no reports of a controlled study with a randomised single population of women. Nuckolls et al, however, have noted a correlation between the prognosis for the outcome of pregnancy and the balance between a woman's social support and the strength and duration of stress during gestation. ${ }^{6}$

Using what is termed "active management of labour," which includes the provision of continuous social support by a midwife for every woman in labour, O'Driscoll and Meagher reported that the 
mean duration of labour for primiparous women was less than six hours. ${ }^{7}$ Only $5 \%$ of the women had labours lasting longer than 10 hours. After active management of labour had been introduced their definition of prolonged labour was reduced from 36 hours to 12 hours. The prevalence of caesarean section varied from $4.0 \%$ to $5 \cdot 3 \%$. The other components of active management include the artificial rupturing of the membranes if labour does not progress according to a predetermined schedule and the use of intravenous oxytocin if the desired progress is not achieved by rupturing the membranes. These measures were used in $30 \%$ of the cases. Although the effect of each of the three components has never been evaluated separately, the continuous support given by the midwife in this system could have effects similar to those observed in our two studies.

We can only speculate about the mechanisms by which social support reduces the duration of labour and perinatal complications. Although the presence of a companion might account for the obstetrician making fewer interventions, it cannot also account for the reduced duration of labour. We favour explanations based on the effects the companion may have on the mother. Adrenaline is known to reduce uterine muscle contractions. ${ }^{8}$ Lederman et al noted a correlation between plasma adrenaline concentrations and self reported anxiety. ${ }^{9}$ Increased concentrations of plasma adrenaline were associated with both anxiety and prolonged duration of labour. By lessening anxiety in women in labour social support may prevent an increase in catecholamine concentrations and thus shorten the duration of labour. Studies in pregnant pigs and monkeys reveal that psychological stress can reduce uterine and placental blood flow and thereby fetal oxygenation. ${ }^{10}{ }^{11}$ By reducing the stress of labour social support might reduce the number of infants admitted for intensive care. If the results of this study can be replicated in other obstetric units in other hospitals present practices may be appreciably altered. This model may be useful in exploring the mechanisms by which support influences physiological processes.

This study was supported by grants from the Thrasher Fund, the Pitway Corporation Charitable Foundation, and the Maternal and Child Health Research (MC-R-390430).

\section{References}

1 Oakley A. Cross-cultural practices. In: Chard T, Richards $M$, eds. Benefits and hazards of the new obstetrics. Lavenham, Suffolk: Spastic International Medical Publications, 1977:18-34.

2 Sosa R, Kennell J, Klaus M, Robertson S, Urrutia J. The effect of a supportive companion on perinatal problems, length of labor, and mother-infant interaction. $N$ Engl $f$ Med 1980;303: perinatal

3 Raphsel D. The tender gift: breastfeeding. Englewood Cliffs: NJ Prentice-Hall, 1973.

4 Dixon WJ, Brown MB, eds. Biomedical computer programs: P-series. Berkeley: University of California Press, 1979.

Murdock GP, White DR. Standard cross-cultural sample. Ethology 1969;8:329-69.

6 Nuckolls KB, Cassel J, Kaplan BH. Psychosocial assets, life crisis and the prognosis of pregnancy. Am $\mathcal{f}$ Epidemiol 1972;95:431-41.

O'Driscoll K, Meagher D. Active Management of Labor. Philadelphia: WB Saunders, 1980.

8 Zuspan FP, Cibels LA, Pose SV. Myometrial and cardiovascular responses for alterations in plasma epinephrine and norepinephrine. Am $\mathcal{f}$ Obstet Gynecol 1962;84:841-51.

9 Lederman RP, Lederman E, Work BA, McCann DS. The relationship of maternal anxiety, plasma catecholamines, and plasma cortisol to progress in labor. Am $\mathcal{J}$ Obstet Gynecol 1978;132:495-500.

10 Barton MD, Killam AP, Meschia G. Response of ovine uterine blood flow to epinephrine and norepinephrine. Proc Soc Exp Biol Med 1974;145:966-1003.

11 Adamsons K, Mueller-Heubach E, Meyers RE. Production of fetal asphyxia in the rhesus monkey by administration of catecholamines to the mother. Am J Obstet Gynecol 1971;109:248-62.

(Accepted 25 fune 1986)
Bulimia is an eating disorder that has been described only recently. Although most of the symptoms are now well known and widely documented, ${ }^{2}$ bulimia is still difficult to detect. ${ }^{3}$ Firstly, patients do not readily admit to having an eating problem because they are ashamed and disgusted by their condition; secondly, secrecy is one of the features of bulimia; and, thirdly, some patients and doctors are still unaware that bulimia is an illness as body weight, shape, and menstruation can all be normal, even in very sick women. Early detection and treatment, however, are essential because bulimia is a potentially fatal but readily treatable condition.

This report describes a severe case of bulimia that occurred in a disguised form that has not been previously reported.

\section{Case report}

A 32 year old divorced woman was referred to a psychiatric outpatient clinic by her general practitioner for insomnia, which she had had for more than a year and for which hypnotic treatment had been ineffective. She said that on "waking" at night she felt confused and began to sleepwalk. She had

St Clement's Hospital, Ipswich IP3 8LS

WAGUIH R GUIRGUIS, MRCPSYCH, consultant psychiatrist. Also honorary lecturer, St George's Hospital Medical School, London put on an excessive amount of weight and was referred to a dietitian. During a recent holiday her insomnia, interestingly, disappeared.

She was given mianserin, but she abandoned this after a week because it made her sleepy only during the day. The patient denied having emotional, work, or marital problems that could have accounted for her state. When a full history was taken, particularly of her eating habits, the real nature of her condition started to unfold. The patient had always been conscious of her body weight and shape and very sensitive to any changes in them. She hated her body, particularly her lower half. She loved food, however, and was a good cook and hostess but was frightened of gaining weight. Consequently, she was always on some form of slimming diet, and her body weight fluctuated widely and quickly. At the time of interview she was on a special diet which gave her no more than $4.2 \mathrm{MJ} /$ day. She had had a very strict family upbringing and had attended a girls' convent school. She had been fat as a child, teased by other girls, and blamed by her mother for eating too many sweets. She never looked at her body, was always ashamed of it, and had often fantasised about chopping off parts of her hips and thighs with a carving knife.

She said: "The funny thing is that I can control my diet all day. I can even go without food at all, but wake up at night, every night, three or four times, sometimes more, walk downstairs, and eat anything I can find. It all seems like a dream but I can't stop or do anything about it. I am completely out of control; I don't even know why or how I stop or how I go back to sleep. A few hours later I wake up again and repeat the same thing... the mess next morning is unbelievable, the empty boxes and food wrappers, the empty fridge, and the larder, . . . a disgrace, I feel ashamed and I hate myself."

She denied, however, feeling any guilt, but admitted to feeling frightened of putting on weight. When asked how she coped with the fear of putting on weight she said: "I never felt sick or made myself sick... I was often tempted though I never used laxatives, but I starve myself next day and spend hours on the bike trying to stop the calories from going into my legs and hips."

Her periods were regular, and she was taking the contraceptive pill. 